\title{
Profile of children admitted with seizures to a tertiary care rural hospital in Mandya district
}

\author{
Shivaprakash $\mathrm{NC}^{1}$, Ahmed $\mathrm{T}^{2}$, Rao $\mathrm{RC}^{3}$ \\ ${ }^{1}$ Dr Shivaprakash NC, Professor and Head of the Department, ${ }^{2}$ Dr Touseef Ahmed, Postgraduate, 3Dr Ravichandra Rao, \\ Postgraduate. All are affiliated with Department of Pediatrics, Adichunchanagiri Institute of Medical Sciences, B.G \\ Nagara, Mandya district, Karnataka, India
}

Address for Correspondence: Dr Touseef Ahmed, Email: drtouseef87ahmed@ gmail.com

\begin{abstract}
Background: Seizures is one of the common causes of pediatric admissions to hospitals with significant mortality and morbidity. As there is limited data on profile regarding acute seizures episodes form the developing countries this study was undertaken. This study aims to assess the age wise distribution, etiology of seizure, classify seizure types and the outcome in children presenting with seizures to our hospital. Methods: This is a hospital based prospective study carried out in the Department of Pediatrics, Adichunchanagiri Institute of Medical Sciences, B.G Nagara, Mandya from 1st June 2014 to 31st May 2015. Parameters such as demographics, clinical presentations, laboratory tests, neuroimaging studies, EEG, diagnosis and course in hospital were assessed. Results: A total of 118 patients were admitted with seizures of which $69(58.47 \%)$ were males and $49(41.52 \%)$ females. Among these patients, $90(76.27 \%)$ presented with fever and $105(88.99 \%)$ children were less than 6 years of age. Generalized seizures were the most common seizure type 81(68.64\%). Febrile seizures 57 (48.30\%), symptomatic seizures 19(16.1\%), seizure disorder 16 (13.55\%), and seizures in cerebral palsy $8(6.8 \%)$ were common etiologies. Conclusions: Acute episode of seizures are one of the commonest cause of hospitalization with high mortality. Febrile convulsions and CNS infections were common causes of seizures in febrile children. Seizures were more common in age 1month to 1year. Neuroimaging should be advised in all afebrile children and in children with partial seizures. CNS infections like meningitis and encephalitis, neurocysticercosis can be prevented with improvement in health care facilities.
\end{abstract}

Keywords: Seizures, Febrile Seizures, CNS Infections, Neuroimaging.

\section{Introduction}

A seizure is a transient occurrence of signs and/or symptoms resulting from abnormal excessive or synchronous neuronal activity in the brain [1]. Seizures account for about $1 \%$ of all emergency department visits, and about $2 \%$ of visits of children's hospital emergency department visits [2]. Seizures are the most common pediatric neurologic disorder, with $4 \%$ to $10 \%$ of children suffering at least one seizure in the first 16 years of life. The incidence is highest in children younger than 3 years of age, with a decreasing frequency in older children [3]. Worldwide, febrile seizures are the most common type of acute seizures in children [4]. In most of the studies, febrile seizures were reported to be the most common type seen in the pediatric population and account for the majority of

Manuscript received: $24^{\text {th }}$ Oct 2015

Reviewed: $5^{\text {th }}$ Nov 2015

Author Corrected: $17^{\text {th }}$ Nov 2015

Accepted for Publication: $3^{\text {rd }}$ Dec 2015 seizures seen in children younger than 5 years of age $[2,4,5]$. Central nervous system (CNS) infections are the main cause of seizures and acquired epilepsy in the developing world [5,6]. Children admitted in emergency department with new onset of non-febrile seizure are often evaluated using cranial computed tomography (CT) [7,8].

Geographical variations determine the common causes in a particular region. Acute seizures are common in meningitis, viral encephalitis and neurocysticercosis $[9,10,11]$. The standardized mortality rate (SMR) in patients with a newly diagnosed unprovoked seizure ranges from 2.5 to 4.1 according to the study population and design. The SMR is highest in the youngest patients and in those with symptomatic seizure [12]. In most children with newly diagnosed epilepsy, the long-term prognosis of epilepsy is favorable, and in particular, 
patients with idiopathic etiology will eventually reach remission [13].

\section{Methods}

All children admitted in the Paediatric ward/ICU with complaints of seizures (including recurrent episodes) in the age group of 1 month to 18 years and children admitted for other complaints and developing seizures during the course of their illness were included. Seizures in developmentally abnormal children were also included. Patients were divided into four age groups: age group (1 month-1 year), (1-3 years), (4-6 years) and (7-18 years).

The following information was obtained from each patient: age, sex, type of seizure, associated symptoms (fever, cough, headache, rashes, vomiting, diarrhea and rhinorrhea etc ), family history of seizure or epilepsy and developmental history. Laboratory test (complete hemogram, CRP, serum electrolytes, RBS) was done. Neuroimaging studies ( Neurosonogram, CT scan head or MRI brain and EEG) and CSF analysis was done wherever indicated and results recorded.

Final outcome was recorded in four categories: discharged after recovery, discharged against medical advice (DAMA), referral to other institutions and mortality. Seizure type classification, including generalized tonic-clonic, absence, myoclonic, partial and other seizures types was based on the Commission on Epidemiology and Prognosis, 1993 International League against Epilepsy [14].

\section{Results}

A total of 118 children were included Table 1(a) of whom the incidence of seizures among different age group was: 1 month to 1 year $40.67 \%$ (48), 1-3 years $34.74 \%$ ( 41 ), $4-6$ years $13.55 \%$ (16) and 7 to 18 years was $11.01 \%(13)$. There were $69(58.47 \%)$ males and $49(41.52 \%)$ females with male to female ratio of 1.4:1. As shown in table 1(b) Fever was notably present in $76.27 \%$ of children at presentation. In generalized seizures, GTCS was seen in 59 (50\%) of the children followed by tonic seizures which were present in $11(9.32 \%)$. Clonic 8 (6.77\%), Myoclonic 2 (1.6\%) and absence seizures $1(0.84 \%)$ were seen less commonly. Among partial seizures, simple partial seizures were noted in 22 (18.6\%), complex partial in 11(9.32\%) and partial seizures with secondary generalization was seen in 4 (3.38\%). Status epilepticus was present in $15(12.71 \%)$ of children. Family history of febrile seizures was present in 8 cases, febrile seizures in $5(4.2 \%)$ and epilepsy in $3(2.5 \%)$ cases.

In the present study febrile seizures were the most commom seizures noted 57 (48.3\%). SFS was found in 35 (61.4\%), AFS in $22(38 \%)$. Symptomatic seizures were in 27 (22.8\%) epilepsy in $16(13.55 \%)$, seizures in cerebral palsy $8(6.8 \%)$, benign neonatal seizures 4 (3.38\%), space occupying lesions in $3(2.54 \%)$ and others $3(2.5 \%)$ of cases.

Among the symptomatic seizures bacterial meningitis 11, viral meningitis 4, TBM 2, encephalitis 2 and hypocalcemic seizures 4 were the common causes. About $103(87.29 \%)$ of the children recovered normally. $8(6.77 \%)$ recovered with deficit, 4 (3.38\%) were referred, 2 (1.69\%) went against medical advice and 1 died (viral Encephalitis).

Table 1(a): Age and Sex distribution data of patients presenting with seizures.

\begin{tabular}{|c|c|c|}
\hline Age & Frequency & Percent \\
\hline 1 month- 1year & 48 & 40.67 \\
\hline $1-3$ yrs & 41 & 34.74 \\
\hline $4-6$ yrs & 16 & 13.55 \\
\hline $7-12$ yrs & 13 & 11.01 \\
\hline Total & 118 & 100 \\
\hline & & \\
\hline Sex & 69 & 58.47 \\
\hline Male & 49 & 41.53 \\
\hline Female & 118 & 100 \\
\hline Total & & \\
\hline
\end{tabular}

Seizures were more common in males compared to females and febrile seizures were most common in 1 - 3 years 29 $(50.9 \%)$ followed by <1 year $25(43.85 \%)$ and $4-5$ years $3(5.26 \%)$ 
Table 1(b): Demographic data of patients presenting with seizures

\begin{tabular}{|l|c|c|}
\hline Type of seizures & Frequency & Percent \\
\hline Generalised & 81 & 68.64 \\
\hline Generalised tonic clonic & 59 & 6.77 \\
\hline Clonic & 8 & 9.32 \\
\hline Tonic & 11 & 1.6 \\
\hline Myoclonic & 2 & 0.84 \\
\hline Absence & 1 & 31.35 \\
\hline Partial & 37 & 18.6 \\
\hline Simple partial & 22 & 9.32 \\
\hline Complex partial & 11 & 3.38 \\
\hline Secondary generalisation & 4 & 100 \\
\hline Total & 118 & 87.29 \\
\hline & & 76.27 \\
\hline Fever & & 23.72 \\
\hline Present & 90 & \\
\hline Absent & 28 & \\
\hline & & \\
\hline Status & 15 & \\
\hline Present & 103 & \\
\hline Absent & & \\
\hline
\end{tabular}

Figure 1: Distribution of seizures according to different etiologies

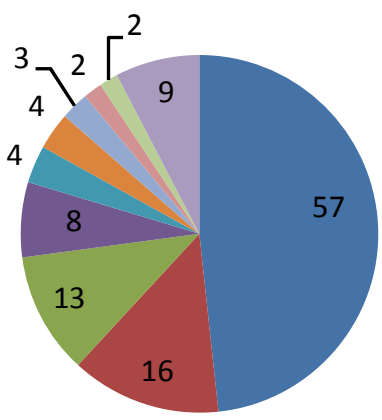

febrile seizures

seizure disorder

bacterial meningitis

cerebral palsy with seizures

- benign neonatal seizures

- hypocalcemic seizures

space occupying lesions

TBM

encephalitis

others

Table 2: Analysis of patients based on age groups

\begin{tabular}{|c|c|c|c|}
\hline & Males & females & Total \\
\hline Seizures & 69 & 49 & 57 \\
\hline Febrile & 32 & 25 & 25 \\
\hline Febrile <1 year & 14 & 11 & 29 \\
\hline Febrile 1- 3 years & 17 & 12 & 3 \\
\hline Febrile 4- 5years & 1 & 2 & 57 \\
\hline
\end{tabular}

Lumbar puncture was performed in 69 children with abnormal reports were seen in 19(27.5\%) children. Neuroimaging was done in $54(45.76 \%)$ children admitted with seizure. Abnormalities were noted in $24(44.4 \%)$ of patients who had undergone imaging. Electroencephalogram (EEG) was done in 48 (40.67\%) children and had abnormal reports in 26 children. 


\section{Discussion}

This was a hospital based prospective study of children admitted with acute onset of seizures in a tertiary care rural hospital of south India. It was aimed in studying demographics, clinical seizure types, etiologies and outcome during the hospital stay of those children.

Demographics and clinical seizure types: As in our study most studies show high incidence of seizures in younger children with a decreasing frequency in older age group and more common in males $[2,6]$. Seizures coexisted with fever in $76 \%$ of cases. Most studies show generalized seizures are much more common compared to partial seizure $[5,8,10]$. In the current study generalized tonic-clonic was commonest seizure type and found to have higher incidence among febrile children. Most studies show generalized seizures are much more common compared to partial seizure $[5,6,10]$ similar to our study. In the current study generalized tonic-clonic seizure was commonest seizure type and partial seizure was common among children more than 7 years. In our study we found that $86 \%$ of children presented with 1 st episode of seizures whereas $14 \%$ of children already had one or more episodes before.

Etiological profile: Whether routine neuroimaging should be done in all children admitted with acute episode of seizure is debated [6,7]. In our study abnormal neuroimaging was present in only 24 (20.34\%). Among SOL, NCC was seen in 2(1.7\%) cases, tuberculoma in $1(0.84 \%)$ cases. Complex Febrile seizures (CFS) did not show any abnormality in CT which correlated with many studies. AAP recommends lumbar puncture for febrile seizure children aged less than 12 months [15].

CSF analysis was done for 69 children and we found abnormality in 19 children, (Bacterial-15/TBM-2/ Viral-2). There are many possible etiologies of a first seizure attack in children, including infection, neurologic/developmental causes, traumatic head injury, toxins, and metabolic disturbances [5,6,9]. Febrile seizures have been reported to be one of the most common causes of seizure attack in children [2, 5].

Primary outcome of acute seizure: There was no significant difference in the outcome among male and female. Fever was not independently associated with increased mortality during the acute illness. Meningitis and encephalitis cause significant childhood mortality and morbidity [5,9]. Children with diagnosis of encephalitis and those with status epileptics had poor outcome with high mortality [16]. In our study 1 child with encephalitis died. Febrile seizure had good outcome with majority of children discharged after recovery. As evident from current study provoked seizures including CNS infections and neurocysticercosis account for a good no 0f cases.

Most of these might be prevented with improvement in sanitation. Attempt should be made to know the burden of other causative organisms for CNS infections and preventive measures should be undertaken. Health care facilities should be prepared for emergency management of seizures to decrease mortality and morbidity.

Limitations of the study: Outcome was defined in terms of mortality during hospital stay and we were unable to study morbidities like neurological dysfunction and impact on scholastic performance. The details of other causes contributing for seizures like inborn error of metabolism were not evaluated due lack of investigations or other issues. Multi centric prospective study with longer follow up is needed to find out details regarding these problems.

\section{Conclusions}

Acute episode of seizures are one of the commonest cause of hospitalization with high mortality. Febrile convulsions and CNS infections were common causes of seizures in febrile children. Seizures were more common in age 1month to 1year. Neuroimaging should be advised in all afebrile children and in children with partial seizures.

CNS infections like meningitis and encephalitis, neurocysticercosis can be prevented with improvement in health care facilities. Group of children presenting with unprovoked seizure require long term follow up studies including neurophysiologic studies and neuroimaging (CT or MRI) for better understanding of childhood seizure disorder in developing countries.

Ethical approval: Obtained from Institutional Ethics Committee (Human Studies)

Funding: No funding sources.

Conflict of Interest: The authors declare no conflict of interest 


\section{References}

1. Kleigman, Stanton, St. Geme, Schor, Behrman. Seizures in childhood. Nelson Textbook of Pediatrics. $20^{\text {th }}$ Ed: Elsevier Saunders; 2015:2823.

2. Martindale JL, Goldstein JN, Pallin DJ. Emergency department seizure epidemiology. Emerg Med Clin North Am. 2011 Feb;29(1):15-27.

3. Friedman MJ, Sharieff GQ. Seizures in children. Pediatr Clin North Am. 2006 Apr;53(2):257-77.

4. Hauser WA. The prevalence and incidence of convulsive disorders in children. Epilepsia 1994;(2):35.

5. Idro R, Gwer S, Kahindi M. The incidence, aetiology and outcome of acute seizures in children admitted to a rural Kenyan district hospital. BMC Pediatr 2008, 8:5. http://www.biomedcentral.com/1471-2431/8/5.

6. Chen CY, Chang YJ, Wu HP. New-onset Seizures in Pediatric Emergency. Pediatr Neonatol. 2010;51(2):103-11.

7. Goldstein JL. Evaluating new onset of seizures in children. Pediatr Ann. 2004;33(6):368-74.

8. Bautovich T, Numa A. Role of head computed tomography in the evaluation of children admitted to the paediatric intensive care unit with new-onset seizure. Emerg Med Australas. 2012;24(3):313-20.

9. Murthy JMK, Yangala R. Acute symptomatic seizures-incidence and etiological spectrum: a hospitalbased study from South India. Seizure. 1999;13:16265 .

\section{How to cite this article?}

Shivaprakash NC, Ahmed T, Rao RC. Profile of children admitted with seizures to a tertiary care rural hospital in Mandya district. Pediatr Rev: Int J Pediatr Res 2015; 2(4):83-87.doi:10.17511/ijpr.2015.i04.09
10. Huang CC, Chang YC, Wang ST. Acute Symptomatic Seizure Disorders in Young Children-A Population Study in Southern Taiwan. Epilepsia. 1998; 13(9):960-64.

11. Basu S, Ramchandran U, Thapliyal A. Clinical profile and outcome of pediatric neuro-cysticercosis: A study from Western Nepal J Pediatr Neurol. 2007;13:45-52.

12. Allen Hauser W, Beghi E. First seizure definitions and worldwide incidence and mortality, Epilepsia. $2008 ; 13(1): 8-12$.

13. Geerts A, Arts WF, Stroink H, Peeters E, Brouwer O, Peters B. Course and outcome of childhood epilepsy: A 15-year follow-up of the Dutch Study of Epilepsy in Childhood. Epilepsia. 2010;13(7):1189-97.

14. Commission on Epidemiology and Prognosis. International League Against Epilepsy. Guideline for epidemiologic studies on epilepsy. Epilepsia. 1993;13:592-96.

15. Academy of Pediatrics. Provisional Committee on Quality Improvement, Subcommittee on Febrile Seizures. Practice parameter. the neurodiagnostic evaluation of the child with a first simple febrile seizure. Pediatr. 1996;13:769-72.

16. Santos MI, Nzwalo H, Monteiro JP, Fonseca MJ. Convulsive status epilepticus in the pediatric emergency department: five year retrospective analysis. Acta Med Port. 2012;25(4):203-06. 